\title{
AKUPRESUR UNTUK MENINGKATKAN KEKUATAN OTOT DAN RENTANG GERAK EKSTREMITAS ATAS PADA PASIEN STROKE
}

\author{
Muhamad Adam $^{1 *}$, Elly Nurachmah ${ }^{1}$, Agung Waluyo $^{1}$
}

1. Fakultas Ilmu Keperawatan, Universitas Indonesia, Depok 16424, Indonesia

*E-mail: adhamners@yahoo.com

\begin{abstract}
Abstrak
Penurunan fungsi ekstremitas atas merupakan komplikasi yang sering terjadi pada pasien pasca stroke yang mengalami hemiplegia sebagai akibat dari kelemahan dan keterbatasan rentang gerak sendi pada bahu. Akupresur bermanfaat dalam memperbaiki fungsi ektremitas atas dengan melancarkan pergerakan aliran qi (energi vital) di dalam tubuh namun belum banyak penelitian yang mengkaji pengaruh akupresur untuk meningkatkan kekuatan otot dan rentang gerak ekstremitas atas pada pasien pasca stroke. Penelitian ini bertujuan untuk mengidentifikasi pengaruh akupresur terhadap kekuatan otot dan tentang gerak ekstremitas atas pada pasien stroke pasca rawat inap. Penelitian ini menggunakan quasi-experimental design dengan pendekatan pre-post test design pada 34 responden ( $\mathrm{n}$ kontrol= $\mathrm{n}$ intervensi= 17). Kelompok intervensi diberi akupresur setiap hari 10 menit selama tujuh hari. Hasil penelitian menunjukkan adanya perbedaan yang bermakna pada kekuatan otot dan rentang gerak ekstremitas atas antara kelompok intervensi dan kelompok kontrol $(p=0,001$ dan $p=0,000 ; \alpha=0,05)$. Akupresur merupakan intervensi yang efektif untuk meningkatkan kekuatan otot dan rentang gerak pada pasien pasca stroke yang mengalami hemiparesis. Rekomendasi pada penelitian ini adalah diperlukan adanya perawat yang menguasai akupresur dan memodifikasi standar asuhan keperawatan dengan memasukkan terapi komplementer akupresur dalam asuhan keperawatan pasien stroke yang mengalami kelemahan dan keterbatasan rentang gerak ekstremitas atas.
\end{abstract}

Kata kunci: akupresur, ekstremitas atas, hemiparesis, kekuatan otot, rentang gerak, stroke

\begin{abstract}
Acupressure to Improve Muscle Strength and Range of Motion of Upper Extremity in Stroke Patients. Decrease in upper extremity function is a frequent complication in patients who experience post-stroke hemiparesis as a result of the weaknesses and limitations of range of motion in the shoulder. Acupressure is useful in improving the function of upper extremity by launching a movement of the flow of qi (vital energy) in the body but not much research that examines the effect of acupressure to improve muscle strength and range of motion of upper extremity in post stroke patients. This study aimed to identify the effect of acupressure on muscle strength and range of motion of upper extremity in stroke patients after hospitalization. This study is a quasi-experimental design with pre-post test approach in 34 respondents $(n$ control $=n$ intervention $=17)$. Acupressure group were given 10 minutes per time each day for 7 days. There are significant differences in muscle strength and range of motion of upper extremity between the intervention group and control group $(p=0,001$ and $p=0,000 ; \alpha=0,05)$. Acupressure is an effective intervention to improve muscle strength and range of motion in patients who experience post-stroke hemiparesis. Recommendations from this finding that nurses need to competent to provide acupressure and modify the standard of nursing care by include acupressure therapy into nursing care of stroke patients who experience upper extremity weakness and range of motion limitations.
\end{abstract}

Keywords: acupressure, upper extremity, hemiparesis, muscle strength, range of motion, stroke

\section{Pendahuluan}

Stroke atau cerebrovascular accident disebabkan oleh putusnya aliran darah ke otak atau oleh karena pecahnya pembuluh darah di otak yang dapat mengakibatkan gangguan muskuloskeletal yang berkontribusi berupa kelemahan otot pada sisi kontralateral dengan lesi di otak (Eng, 2004).
Berdasarkan hasil Riset Kesehatan Dasar 2013 (Kementrian Kesehatan RI, 2013), stroke merupakan penyebab kematian utama di Indonesia. Prevalensi stroke di Indonesia berdasarkan diagnosis tenaga kesehatan sebesar 7,0 per mil dan berdasarkan diagnosis tenaga kesehatan atau gejala sebesar 12,1 per mil. Sebanyak 57,9 persen penyakit stroke telah terdiagnosis. 
Stroke secara jelas dapat berdampak pada penurunan fungsi ekstremitas atas berupa kehilangan kontrol ektremitas atas yang dapat menurunkan kekuatan otot dan rentang gerak serta merupakan komplikasi yang yang paling sering terjadi, yaitu sebanyak $88 \%$ pasien pasca stroke (AHA, 2007; Zeferino \& Aycock, 2010; Borisova \& Bohannon, 2009).

Komplikasi ini dapat berlangsung lama dan akan memengaruhi kualitas hidup pasien dan keluarganya karena fungsi ekstremitas atas merupakan hal yang fundamental dalam melakukan aktivitas sehari-hari (Opara, \& Jaracz, 2010). Oleh karena itu, perlu penanganan yang lebih komprehensif.

Ada beberapa terapi yang dapat dimanfaatkan oleh pasien pasca stroke seperti latihan lengan dan pemberian posisi (Desroiers et al, 2005; \& Yelena \& Bohannon, 2009). Terapi akupresur terutama meridian acupressure terbukti merupakan intervensi yang efektif untuk memperbaiki pergerakan ektremitas atas, meningkatkan aktivitas sehari-hari, dan mengurangi depresi pada pasien strike hemiplegia stroke di Korea (Kang, Sok, \& Kang, 2009). Penelitian tersebut menguji terapi akupresur 10 menit setiap hari dalam waktu dua pecan. Akupresur adalah intervensi yang dapat dilakukan oleh perawat dan telah diakui sebagai tindakan keperawatan dalam Nursing Intervention Classifications (Dochterment \& Bulecheck, 2004).

Akupresur merupakan metode non-invasif berupa penekanan pada titik akupunktur tanpa menggunakan jarum, biasanya hanya menggunakan jari atau benda tertentu yang dapat memberikan efek penekanan sehingga lebih bisa diterima dan ditoleransi oleh pasien dibandingkan akupunktur yang menggunakan jarum (Alkaissi, Stalnert, \& Kalman, 2002; Black \& Hawk, 2009; Lemone $\&$ Burke, 2008; \& Ming et al., 2002).

Akupresur bermanfaat dalam memperbaiki fungsi ektremitas atas melalui efeknya untuk melancarkan pergerakan aliran qi (energi vital) di dalam tubuh (Sebastian, 2009). Titik-titik akupunktur terkait fungsi ekstremitas atas (Gambar 1)

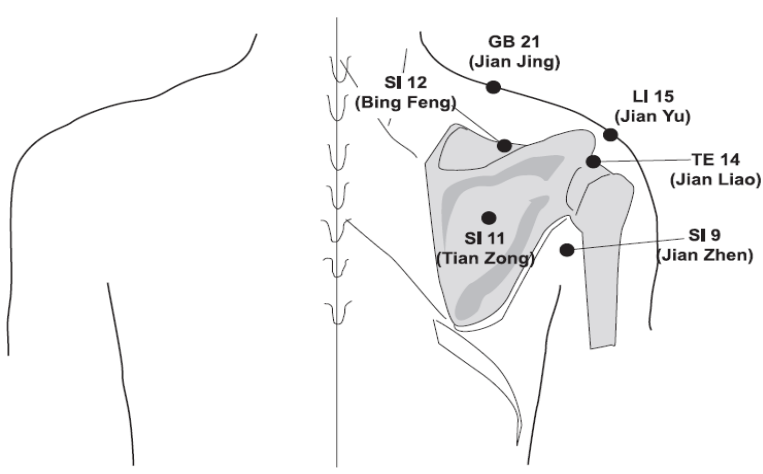

Gambar 1. Titik Akupresur Fungsi Ektremitas Atas (Sumber: Shin \& Lee, 2007)

terdapat pada area skapula, yaitu Large Intestine 15, Small Intestine 9, Triple Energizer 14, Gallbladder 21, Small Intestine 11 dan Small Intestine 12. (Sin \& Lee, 2007).

Meskipun, manfaat akupresur telah diuji pada penelitian di Korea, pada populasi di Indonesia perlu dilakukan penelitian kembali dengan metode yang lebih singkat, yaitu selama tujuh hari. Penelitian ini bertujuan untuk mengidentifikasi pengaruh akupresur terhadap kekuatan otot dan tentang gerak ekstremitas atas pada pasien stroke pasca rawat inap.

\section{Metode}

Penelitian ini menggunakan metode kuasi eksperimental dengan pendekatan control groups pretest-post test design yang melibatkan 34 pasien stroke pasca rawat inap. Kriteria inklusi responden, antara lain terdiagnosis stroke baik hemoragik maupun non-hemoragik, mengalami hemiparesis dengan kekuatan otot 1-3 baik kiri maupun kanan, kesadaran kompos mentis dan bersedia mengikuti penelitian. Sedangkan kriteria eksklusi dari penelitian ini yaitu tanda-tanda vital tidak stabil, pasien dalam fase akut (kurang dari 7 hari onset serangan) dan kontraindikasi akupresur (kulit terluka, bengkak, fraktur, myalgia).

Pengambilan sampel dilakukan dengan metode consecutive sampling yaitu pasien yang datang dan telah menjalani perawatan di RSUP Fatmawati serta memenuhi kriteria dimasukkan sebagai subyek penelitian. 
Sampel terbagi menjadi 2 kelompok yaitu kelompok intervensi dan kelompok kontrol yang masing-masing berjumlah 17 orang. Penetapan kelompok intervensi dan kontrol dilakukan dengan penomoran berdasarkan urutan pasca perawatan. Jika bernomor genap masuk ke kelompok intervensi dan jika bernomor ganjil masuk ke kelompok kontrol.

Intervensi dilakukan dengan memberikan akupresur 10 menit pada keenam titik akupunktur di regio skapula (lihat Gambar 1), sekali sehari selama tujuh hari di rumah responden, sedangkan kelompok kontrol tidak diberi akupresur. Data yang dikumpulkan terdiri atas karakteristik, kekuatan otot, dan rentang gerak ekstremitas atas.

Karaktersitik responden, yang meliputi usia, jenis kelamin, tipe stroke, frekuensi stroke dan admission time (waktu yang dibutuhkan ke rumah sakit sejak mendapatkan serangan stroke).

Kekuatan otot ekstremitas, diukur dengan meminta responden mengangkat ekstremitas atasnya yang mengalami hemiparesis dan dinilai dengan menggunakan Medical Research Council Scale yang terdiri dari 6 tingkat, mulai dari 0 (tidak ada kontraksi) sampai 5 (kekuatan normal).

Rentang gerak ekstremitas atas, diukur dengan menggunakan goniometer pada 5 gerakan dasar sendi ekstremitas atas yaitu rotasi eksterna bahu: $90^{\circ}$, fleksi bahu: $180^{\circ}$, abduksi bahu: $180^{\circ}$, ekstensi siku: $180^{\circ}$ dan supinasi lengan: $90^{\circ}$. Hasil pengukuran berupa rerata dari kelima persentasi gerakan maksimum yang dilakukan pada setiap rentang gerak.

Pengukuran kekuatan otot dan rentang gerak ekstremitas atas dilakukan dua kali, sebelum dan sesudah diberikan intervensi. Analisis data dilakukan dengan bantuan program komputer. Uji homogenitas antara kelompok intervensi dan kontrol menggunakan uji chi-square untuk data jenis kelamin, tipe stroke, frekuensi stroke dan admission time, serta uji $t$ independent untuk usia. Perbedaan kekuatan otot antara kelompok intervensi dan kontrol dinilai dengan meng- gunakan uji Wilcoxon dan untuk perbedaan rentang gerak menggunakan uji $t$ independent.

Penelitian dilaksanakan stelah memperoleh ijin lolos etik dari Fakultas Ilmu Keperawatan Universitas Indonesia dan surat ijin penelitian dari sebuah RSU tempat penelitian di Jakarta. Selama kegiatan penelitian, nama responden tidak digunakan namun hanya menggunakan nomor responden. Pasien dan keluarga telah diberikan informasi tentang tujuan penelitian, prosedur penelitian dan hak-hak responden termasuk hak untuk mengundurkan diri dari penelitian kapanpun diinginkan jika merasakan ketidaknyamanan.

\section{Hasil}

Karakteristik Responden. Rerata usia responden antara kelompok intervensi dan kelompok kontrol hampir sama. Rerata usia pada kelompok kontrol sebesar 62,53 tahun sedangkan pada kelompok kontrol sebesar 63,88 tahun (Tabel 1).

Proporsi perempuan lebih banyak dibandingkan laki-laki baik pada kelompok intervensi maupun kontrol. Proporsi stroke non-hemoragik lebih banyak dibandingkan dengan stroke hemoragik baik pada kelompok intervensi maupun kelompok kontrol. Stroke yang diderita responden hampir seluruhnya adalah serangan pertama dan mayoritas responden tiba di rumah sakit lebih dari 6 jam setelah mengalami serangan baik pada kelompok intervensi maupun kelompok kontrol (Tabel 2).

Uji Homogenitas. Hasil analisis yang terlihat pada Tabel 3 menunjukkan bahwa antara kelompok intervensi dan kelompok kontrol tidak memiliki perbedaan rerata usia yang bermakna atau rerata usia setara/homogen antara kelompok intervensi dan kontrol ( $p>0,05)$.

Tabel 1. Hasil Analisis Usia Responden di RSUP Fatmawati Jakarta Meni-Juni $2011(\mathrm{n}=34)$

\begin{tabular}{llllll}
\hline Variabel & Kelompok & n & Mean & SD & $\begin{array}{c}\text { Min - } \\
\text { Mak }\end{array}$ \\
\hline \multirow{2}{*}{ Usia } & Intervensi & 17 & 62,53 & 14,45 & $26-85$ \\
& Kontrol & 17 & 63,88 & 11,07 & $39-85$ \\
\hline
\end{tabular}


Hasil analisis pada Tabel 4 menunjukkan bahwa antara kelompok intervensi dan kelompok kontrol tidak memiliki perbedaan yang bermakna berdasarkan jenis kelamin, tipe stroke, frekuensi stroke dan admission time ( $\mathrm{p}>0,05)$.

Hasil analisis menunjukkan rerata rentang gerak ekstremitas atas antara kelompok intervensi dan kontrol sebelum dilakukan intervensi hampir sama. Analisis lebih lanjut menunjukkan bahwa tidak ada perbedaan rentang gerak yang bermakna antara kelompok intervensi dan kelompok kontrol sebelum dilakukan akupresur $(p>0,05)$.

Hasil analisis menunjukkan tidak terdapat perbedaan yang signifikan kondisi kekuatan otot ekstremitas atas pada kelompok intervensi dan kontrol ( $p>0,05)$. Dengan kata lain, kekuatan otot ekstremitas atas sebelum dilakukan aku-

Tabel 2. Jenis Kelamin, Tipe Stroke, Frekuensi Stroke dan Admission Time

\begin{tabular}{|c|c|c|c|c|}
\hline \multirow[t]{2}{*}{ Variabel } & \multicolumn{2}{|c|}{$\begin{array}{c}\text { Intervensi } \\
(\mathbf{n}=17)\end{array}$} & \multicolumn{2}{|c|}{$\begin{array}{c}\text { Kontrol } \\
(n=17)\end{array}$} \\
\hline & $\mathbf{n}$ & $\%$ & $\mathbf{n}$ & $\%$ \\
\hline \multicolumn{5}{|l|}{ Jenis Kelamin } \\
\hline a. Laki-laki & 8 & 47,1 & 7 & 41,2 \\
\hline b. Perempuan & 9 & 52,9 & 10 & 58,8 \\
\hline Total & 17 & 100,0 & 17 & 100,0 \\
\hline \multicolumn{5}{|l|}{ Tipe Stroke } \\
\hline a. Non Hemoragik & 14 & 82,6 & 15 & 88,2 \\
\hline b. Hemoragik & 3 & 17,6 & 2 & 11,8 \\
\hline Total & 17 & 100,0 & 17 & 100,0 \\
\hline \multicolumn{5}{|l|}{ Frekuensi Stroke } \\
\hline a. Serangan I & 15 & 88,2 & 16 & 94,1 \\
\hline b. Serangan II \& & & & & \\
\hline Seterusnya & 2 & 11,8 & 1 & 5,9 \\
\hline Total & 17 & 100,0 & 17 & 100,0 \\
\hline Admission Time & 2 & 11,8 & 1 & 5,9 \\
\hline a. $\leq 6 \mathrm{jam}$ & 15 & 88,2 & 16 & 94,1 \\
\hline b. $>6 \mathrm{jam}$ & 17 & 100,0 & 17 & 100,0 \\
\hline Total & & & & \\
\hline
\end{tabular}

Tabel 3. Uji Homogenitas Usia Responden pada Kelompok Intervensi dan Kelompok Kontrol

\begin{tabular}{llccc}
\hline Variabel & Kelompok & $\mathbf{n}$ & $\mathbf{t}$ & $\boldsymbol{p}$ \\
\hline \multirow{2}{*}{ Usia } & Intervensi & 17 & 0,76 & 0,761 \\
& Kontrol & 17 & & \\
\hline
\end{tabular}

presur setara atau homogen antara kelompok intervensi dan kelompok kontrol.

Hasil analisis menunjukkan bahwa kekuatan otot pada kelompok intervensi lebih besar jika dibandingkan dengan kekuatan otot pada kelompok kontrol setelah dilakukan akupresur.

Analisis lebih lanjut menunjukkan adanya perbedaan kekuatan otot yang bermakna antara kelompok intervensi dan kelompok kontrol setelah dilakukan akupresur $(\mathrm{p}<0,05)$.

Tabel 4. Homogenitas Jenis Kelamin, Tipe Stroke, Frekuensi Stroke dan Admission Time pada Kelompok Intervensi dan Kelompok Kontrol

\begin{tabular}{|c|c|c|}
\hline Variabel & $X^{2}$ & $p$ \\
\hline $\begin{array}{l}\text { Jenis Kelamin } \\
\text { Perempuan } \\
\text { Laki-laki }\end{array}$ & 0,000 & 1,000 \\
\hline $\begin{array}{l}\text { Tipe Stroke } \\
\quad \text { Non Hemoragik } \\
\text { Hemoragik }\end{array}$ & 0,163 & 0,686 \\
\hline $\begin{array}{l}\text { Frekuensi Stroke } \\
\text { Serangan I } \\
\text { Serangan II \& seterusnya }\end{array}$ & 0,000 & 1,000 \\
\hline $\begin{array}{l}\text { Admission Time } \\
\leq 6 \text { jam } \\
>6 \text { jam }\end{array}$ & 0,000 & 1,000 \\
\hline
\end{tabular}

Tabel 5. Uji Homogenitas Kekuatan Otot Sebelum Intervensi pada Kelompok Intervensi dan Kontrol

\begin{tabular}{ccccc}
\hline Variabel & n & $\begin{array}{r}\text { Mean } \\
\text { Rank }\end{array}$ & $\boldsymbol{Z}$ & $\boldsymbol{p}$ value \\
\hline Kekuatan Otot & & & & \\
Intervensi & 17 & 16,56 & $-0,635$ & 0,525 \\
Kontrol & 17 & 18,44 & & \\
\hline
\end{tabular}

Tabel 6. Uji Homogenitas Rentang Gerak Ekstremitas Atas Sebelum Intervensi pada Kelompok Intervensi dan Kontrol

\begin{tabular}{cccccc}
\hline Variabel & n & Mean & SD & t & $\boldsymbol{p}$ \\
\hline Rentang Gerak & & & & & \\
Intervensi & 17 & 75,33 & 6,89 & 0,96 & 0,344 \\
Kontrol & 17 & 77,03 & 2,39 & & \\
\hline
\end{tabular}


Tabel 7. Perbandingan Kekuatan Otot Ekstremitas Atas Setelah Akupresur pada Kelompok Intervensi dan Kontrol

\begin{tabular}{ccccc}
\hline Variabel & n & $\begin{array}{c}\text { Mean } \\
\text { Rank }\end{array}$ & $\boldsymbol{Z}$ & $\begin{array}{c}\boldsymbol{p} \\
\text { value }\end{array}$ \\
\hline Kekuatan Otot & & & & \\
Intervensi & 17 & 22,82 & 3,456 & $0,001^{*}$ \\
Kontrol & 17 & 12,18 & & \\
* bermakna pada $\alpha 0,05$ dengan Uji Mann-Withney U
\end{tabular}

Tabel 8. Perbandingan Rentang Gerak Ekstremitas Atas Setelah Akupresur pada Kelompok Intervensi dan Kontrol

\begin{tabular}{lccccc}
\hline \multicolumn{1}{c}{ Variabel } & $\mathbf{n}$ & Mean & SD & t & p value \\
\hline $\begin{array}{l}\text { Rentang } \\
\text { Gerak }\end{array}$ & & & & & \\
$\quad$ Intervensi & 17 & 84,80 & 5,66 & & \\
Kontrol & 17 & 76,86 & 2,17 & 5,41 & $0,000^{*}$ \\
\hline * bermakna pada $\alpha$ & 0,05 & & & &
\end{tabular}

Hasil analisis pada Tabel 8 menunjukkan rerata rentang gerak pada kelompok intervensi lebih besar jika dibandingkan dengan rerata rentang gerak pada kelompok kontrol setelah dilakukan akupresur. Rerata rentang gerak pada kelompok intervensi setelah dilakukan akupresur sebesar 84,80 dengan standar deviasi 5,66; sedangkan rerata rentang gerak pada kelompok kontrol setelah dilakukan intervensi sebesar 76,86 dengan standar deviasi 2,17. Analisis lebih lanjut menunjukkan adanya perbedaan rerata rentang gerak yang bermakna antara kelompok intervensi dan kelompok kontrol setelah dilakukan akupresur $(\mathrm{p}<0,05 ; \alpha 0,05)$.

\section{Pembahasan}

Kekuatan Otot Ekstremitas Atas. Rerata kekuatan otot ektremitas atas setelah akupresur pada kelompok intervensi lebih besar dibandingkan dengan kelompok kontrol. Hasil penelitian ini telah menunjukkan bahwa akupresur yang dilakukan dapat meningkatkan skor kekuatan otot ekstremitas atas pada responden yang mengalami kelemahan kekuatan otot akibat stroke hemiparetik.
Akupresur pada titik akupresur yang berada di atas regio skapula dapat meningkatkan kekuatan otot ekstremitas atas secara bermakna pada pasien pasca stroke. Sebagaimana dikemukakan Shin dan Lee (2007) bahwa titik akupresur yang berada pada regio skapula memiliki hubungan yang sangat erat dengan titik trigger untuk memperbaiki fungsi ekstremitas atas. Titik trigger merupakan titik sensitif yang bila ditekan akan menimbulkan nyeri pada tempat yang jauh dari titik tersebut, dimana titik ini merupakan degenerasi lokal di dalam jaringan otot yang diakibatkan oleh spasme otot, trauma, ketidakseimbangan endokrin dan ketidakseimbangan otot. Titik trigger dapat ditemukan pada otot rangka dan tendon, ligamen, kapsul sendi, periosteum dan kulit. Otot yang normal tidak mempunyai titik trigger.

Rentang Gerak Ekstremitas Atas. Rerata rentang gerak ektremitas atas setelah dilakukan akupresur pada kelompok intervensi lebih tinggi dibandingkan dengan kelompok kontrol. Akupresur yang dilakukan dapat meningkatkan skor rentang pada responden yang mengalami keterbatasan rentang gerak akibat stroke hemiparetik.

Kang, et al., (2009) mengemukakan bahwa pemberian akupresur pada titik meridian dapat memperbaiki sirkulasi $q i$ dan darah dalam tubuh, sehingga akan merelaksasikan otot yang mengeras dan merangsang perbaikan alamiah pada abnormalitas skeletal dan rentang gerak dapat meningkat.

Selain itu, dikemukakan pula bahwa pemberian terapi akupresur akan mengharmonisasikan aliran $q i$ dan darah sehingga akan merelaksasikan spasme dan meredakan nyeri pada sendi karena menstimulasi pelepasan endorphin (East-West Nursing Research Association, 2001; Kang et al., 2009).

Ditemukan adanya kecenderungan penurunan rentang gerak pada kelompok kontrol dari $77 \%$ turun menjadi $76,9 \%$ dalam waktu 1 pekan terutama pada gerakan sendi bahu rotasi ekstrena bahu dan abduksi bahu karena secara fisiologis pada pasien yang mengalami hemiparesis akan 
mengalami penurunan rentang gerak, khususnya pada persendian bahu jika tidak diberikan terapi.

Borisova \& Bohannon (2009) berpendapat bahwa sendi bahu pasien pada sisi tubuh yang mengalami kelumpuhan akan mengalami keterbatasan rentang gerak terutama keterbatasan pada rotasi eksternal bahu pada sisi tubuh yang lumpuh. Kerusakan rentang gerak akan terjadi segera setelah serangan stroke dan semakin memburuk seiring berjalannya waktu. Penjelasan logis untuk penurunan rentang gerak yang progresif ini telah diobservasi sangat memengaruhi keterbatasan sendi secara signifikan.

\section{Kesimpulan}

Hasil penelitian ini telah dapat menjawab tujuan penelitian, yaitu mengidentifikasi pengaruh akupresur terhadap kekuatan otot dan tentang gerak ekstremitas atas pada pasien stroke pasca rawat inap. Penelitian ini memberikan bukti bahwa akupresur dapat meningkatkan kekuatan otot dan rentang gerak ekstremitas atas. Oleh karena itu, terapi akupresur perlu diterapkan sebagai salah satu intervensi keperawatan terutama pada pasien stroke.

Diperlukan sumber daya perawat yang memiliki kompetensi dalam memberikan terapi akupresur sehingga terapi komplementer ini dapat diaplikasikan kepada pasien stroke yang mengalami kelemahan otot dan keterbatasan rentang gerak pada ekstremitas atasnya baik di rumah sakit maupun rawat jalan.

Hasil penelitian ini dapat berkontribusi dalam memberlakukan SOP (Standar Operasional Prosedur) yang komprehensif yang memungkinkan perawat memberikan asuhan keperawatan dengan tindakan mandiri berupa akupresur ini.

Walaupun terapi akupresur pada penelitian ini terbukti efektif, terapi akupresur tidak dimaksudkan sebagai terapi pengganti pengobatan konvensional tetapi sebagai terapi pelengkap atau komplementer bagi terapi lainnya yang memiliki tujuan yang sama dalam meningkatkan kekuatan otot dan rentang gerak ekstremitas atas.
Pembuktian efektifitas akupresur dalam penelitian ini menjadi salah satu evidence based practice yang akan semakin memperkuat dukungan teoritis bagi perkembangan terapi komplementer dalam ilmu keperawatan medikal bedah, sehingga dapat dijadikan sebagai materi dalam pembelajaran keperawatan medikal bedah.

Keterbatasan penelitian ini adalah tidak menguji adanya faktor lain yang mungkin juga memengaruhi kekuatan otot dan rentang gerak ekstremitas atas pada pasien stroke. Penelitian ini juga hanya mengambil sampel pasien stroke di rumah sakit ketika rawat inap, tidak kepada pasien pada masa rehabilitasi setelah dipulangkan.

Hasil penelitian ini dapat dijadikan sebagai rujukan tentang pengaruh akupresur terhadap kekuatan otot dan rentang gerak ekstremitas atas pada pasien pasca stroke. Hasil penelitian ini juga dapat memberikan pengetahuan baru bagi penelitian keperawatan dan dapat menjadi rujukan untuk penelitian selanjutnya $(\mathrm{JH}, \mathrm{AW})$

\section{Ucapan Terima Kasih}

Ucapan terima kasih ditujukan kepada Direktur Rumah Sakit Umum tempat penelitian berlangsung dan para responden atas kerjasama dan dukungannya.

\section{Referensi}

Alkaissi, A., Stalnert, M., \& Kalman, S. (2002). Effect and placebo effect of acupressure (P6) on nausea and vomiting after outpatient gynaecological surgery. Acta Anaestheseologica Scandinavia, 43, 3, 270-274.

American Heart Association. (2007). Let's talk about complication after stroke. Mei 2, 2011. http://www. strokeassociation.org/idc/groups/ stroke.

Black, J. M., \& Hawk, J. H. (2009). Medical surgical nursing: clinical management for positive outcomes (Vol 2, 8th Ed.). St. Louis: Saunders Elsevier. 
Borisova, Y. \& Bohannon, R. W. (2009). Positioning to prevent or reduce shoulder range of motion impairments after stroke: A meta-analysis. Clinical Rehabilitation, 23(8), 681-690.

Desrosiers , J., Bourbonnais, D., Corriveau, H., Grosselin, S., \& Bravo, G. (2005). Effectiveness of unilateral and symmetrical bilateral task training for arm during the subacute phase after stroke: A randomized controlled trial. Clinical Rehabilitation, 19, 581-593.

Dochterman, J. M., \& Bulecheck, G. M. (2004). Nursing interventions classification (NIC) (4th Ed.). St. Louis, Missouri: Mosby Elsevier

East-West Nursing Research Institute. (2001). East-west nursing mediation. Seoul: Hyun Moon Sa.

Kang, H. S., Sok, S. R., Kang, J. S. (2009). Effects of meridian acupressure for stroke patient in Korea. Journal of Clinical Nursing, 18, 21452151.

Kementerian Kesehatan RI. (2013). Riset Kesehatan Dasar: Riskedas 2013. Jakarta: Balitbangkes Kemkes RI. Diperoleh dari: http://www.depkes. go.id/resources/download/general/Hasil\%20Ris kesdas\%202013.pdf
LeMone, P., \& Burke, K. (2008). Medical surgical nursing: Critical thinking in client care (4th Ed.). USA: Pearson Prentice Hall.

Ming, J. L., Kuo, B.I., Lin, J., \& Lin, L. (2002). The efficacy of acupressure to prevent nausea and vomiting in post-operative patients. Journal of Advanced Nursing, 39(4), 343-351.

Opara, J., \& Jaracz, K. (2010). Quality of life of post-stroke patients and their caregivers . Journal of Medicine and Life, 3(3), 216-220.

Sebastian, H.T. (2009). Rehabilitasi Stroke. March 1, 2011. http://www. akupresur.com/

Shin, B. C. \& Lee, M. S. (2007). Effects of aromatherapy acupressure on hemiplegic shoulder pain and motor power in stroke patients: A pilot study. The Journal of Alternative And Complementary Medicine, 13 (2), 247-251.

Yelena, B., \& Bohannon R. W. (2009). Positioning to prevent or reduce shoulder range of motion impairments after stroke: A Meta-analysis. Clinical Rehabilitation, 23(8), 681-691.

Zeferino, S. I. \& Aycock, D. M. (2010). Poststroke shoulder pain: Inevitable or preventable? Rehabilitation Nursing, 35 (4), 147. 